\title{
What is hypertension? Recent studies on neurogenic hypertension
}

\author{
Peter Sleight \\ From the Cardiac Department, Radcliffe Infirmary, Oxford
}

The indirect measurement of arterial pressure is deceptively easy; for the last 70 years it has been almost an obsession for practising physicians.

The identification of a small group of cases of hypertension secondary to other diseases resulted in an enormous effort to discover a cause or causes for all cases of hypertension. This proved elusive, and Pickering (1968) questioned, 'Did the Holy Grail really exist?'

It is perhaps fortunate that I do not have the time or space to comment on all aspects of this question, for as a relative newcomer to the field I am not qualified to do so. I therefore propose to deal mainly with the influence of the nervous system, particularly the autonomic nerves, on arterial blood pressure, reviving the interest of the investigators of the 1930's.

Before doing so I should attempt to give a brief answer to the question, 'What is hypertension?' Increasing evidence from population surveys and life assurance statistics supports Pickering's view that blood pressure is a continuously distributed variable in the population; that the cardiovascular consequences which we know as hypertensive disease are closely and quantitatively related to the level of arterial pressure; and that this level of pressure is determined by many factors, some genetic, some environmental, and all poorly understood. We shall see from the evidence of other contributors this morning that lowering the arterial pressure reverses the disease processes and prolongs life. The difficulty under these circumstances is to define normal. The same dilemma is seen with another quantity - the serum cholesterol. This too varies considerably with race and environment; there is the same difficulty in defining normality.

I return to the nervous system. After the discovery by Hering of the reflex control of blood pressure by the carotid sinuses it was thought possible that so-called essential hypertension was a consequence of disease or dysfunction of these reflexes. This position was gradually eroded when experimental neurogenic hypertension in animals was found to be variable and sometimes transient. It differed from established essential hypertension in that it was associated with a tachycardia (Koch and Mies, 1929; Boyd and McCullogh, 1938). Furthermore, in man, Pickering, Kissin, and Rothschild (1936) found by digital compression of the carotid sinus that the reflex was active in essential hypertension. Later McCubbin, Green, and Page (1956) demonstrated that the activity of the carotid sinus nerves of renal hypertensive dogs was 'reset', so that there was a normal pulsatile discharge at the new higher pressure, instead of the continuous maximal discharge to be expected if the receptors had not 'reset'. Christensen, Warner, and Pryor (1967) reported very rapid resetting of the receptor to a change in sinus pressure. Later Aars $(1968 \mathrm{a}, \mathrm{b})$ qualified and quantitated this work, showing in hypertensive rabbits that the receptors were less sensitive as well as reset.

Our group at Oxford became interested again in the autonomic control of blood pressure as a result of the work of Richardson et al. (1964), who described the fall in blood pressure which occurs in sleep. We investigated the behaviour of the baroreceptor reflex in normal and hypertensive man awake, anaesthetized, and asleep (Smyth, Sleight, and Pickering, 1969; Bristow et al., 1969a, b). The method related the reflex cardiac slowing to a transient rise in arterial pressure produced by the sudden intravenous injection of angiotensin or phenylephrene. A linear relation is obtained when the systolic pressure of a pulse beat is plotted against the pulse interval which follows. Thus the slope of this line (in msec. increase in pulse interval for $\mathrm{I} \mathrm{mm}$. Hg rise in systolic pressure) is used as an index of the sensitivity of the complete baroreflex arc.

Contrary to the earlier studies reported above, we found a clear decrease in the sensitivity of the reflex when the subject was hyper- 


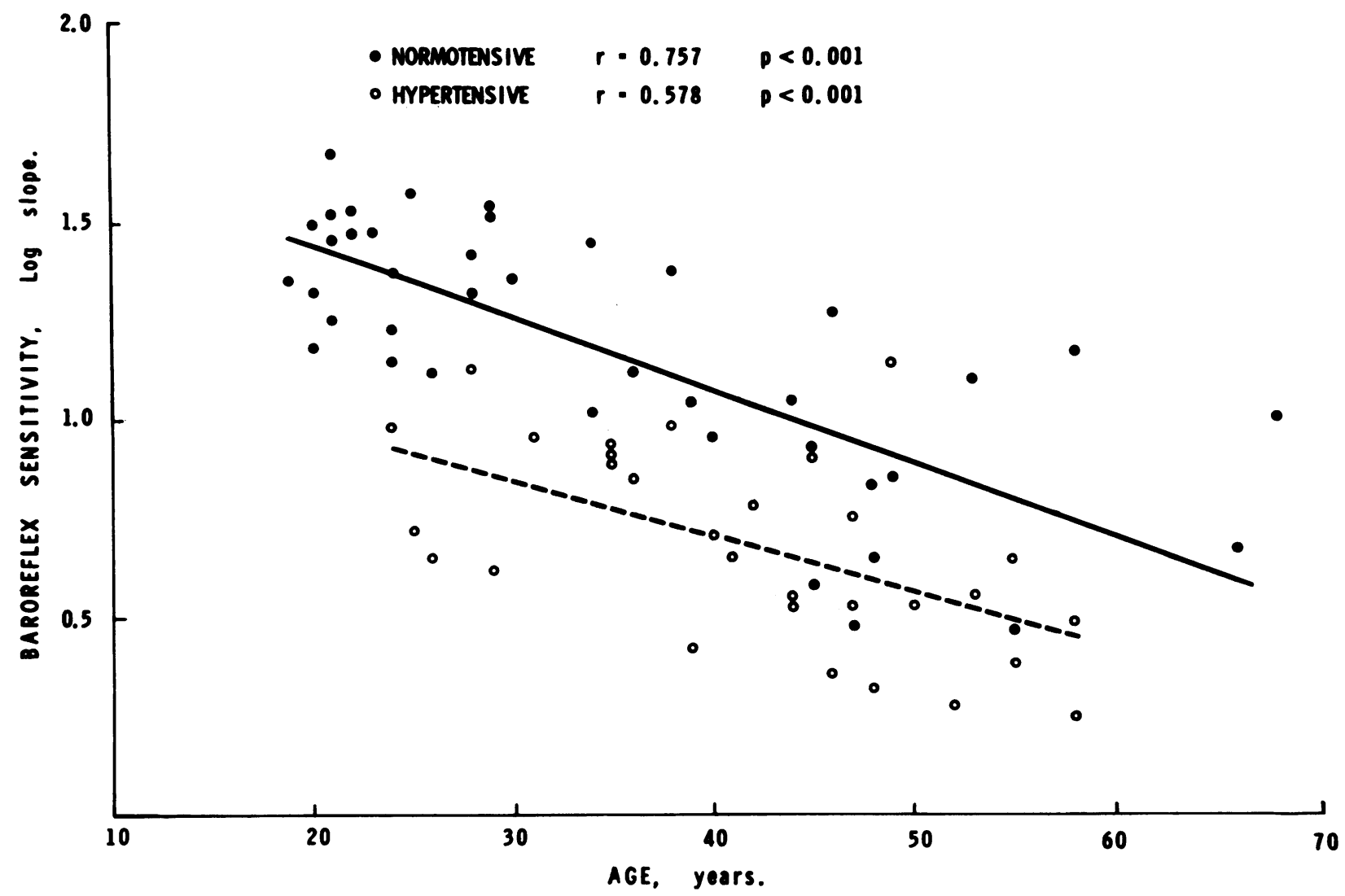

FIG. I The relation between the subject's age and reflex sensitivity. Each dot represents the mean value for one subject. Normotensive and hypertensive subjects are arbitrarily separated above and below a mean arterial pressure of $100 \mathrm{~mm}$. $\mathrm{Hg}$, and the regression of mean blood pressure on sensitivity for each group expressed by the continuous and broken lines, respectively.

tensive. Like G. W. Pickering we could not distinguish two groups - normal and hypertensive; rather was there a steady decrease in sensitivity with increasing arterial pressure. More recently we have also found a similar decrease with increasing age of the subject (Fig. I) (B. Gribbin, T. G. Pickering, and P. Sleight, 1970, unpublished).

During sleep, like Richardson et al. (1964), we found a decrease in blood pressure; this averaged about to per cent in both normotensive and hypertensive subjects (arbitrarily divided at a mean arterial pressure of roo $\mathrm{mm}$. $\mathrm{Hg}$ ). The fall during sleep was almost entirely due to a decrease in peripheral resistance, probably associated with a withdrawal of sympathetic tone. Certainly we found a fall in blood pressure synchronous with the onset of sleep itself, as defined from the electroencephalogram. Khatri and Freis (1967) found a fall in cardiac output with sleep.

It might be argued, therefore, that the lack of a quantitative difference between the fall in pressure in hypertensive compared with normotensive subjects means that there is no evidence of a neurogenic factor in the genesis of hypertension. It should be remembered, however, that there is a great deal of evidence that hypertension, once established, leads to permanent changes in the circulation which do not revert when the original cause (e.g. renal artery stenosis) is removed. Sivertsson (1970) cites evidence that an increased wall/ lumen ratio is present in well-established human essential hypertension and discusses how this may be the end result of previous increases in sympathetic tone. There is also experimental evidence that the first stage of the development of experimental renal hypertension is an increase in cardiac output. This is followed by an increase in peripheral resistance which brings the cardiac output back to normal while the pressure remains elevated (Ledingham and Cohen, 1963). The mechanism of the subsequent autoregulation is not clearly understood. Conway (1969) has recently reviewed the evidence in man compatible with this 
view and has added data of his own (Julius and Conway, 1968) which suggest that in younger subjects raised arterial pressure is associated with a high cardiac output. Lund-Johansen (1967) in a population survey in Bergen also reported a high cardiac output. Both these studies showed that even in these younger subjects with raised pressure and high output the peripheral resistance did not fall normally with exercise.

Thus in future studies of the effect of sleep on blood pressure it may be important to allow for this influence of age. It may be particularly in the young that sympathetic tone is abnormally high, although it should be pointed out that studies of catecholamine excretion have usually shown normal values in established hypertension.

I have reported above that we found also a clear decrease in baroreflex sensitivity with increasing arterial pressure. It is therefore tempting to speculate that the long-term level of arterial pressure is indeed controlled by the baroreflexes. However, at present it appears more likely that high arterial pressure inactivates the baroreceptors. It may do this by two mechanisms: (a) by damage to nerve elements in the arterial wall (Ábráham, 1969); (b) by increasing arterial wall stiffness either by early infiltration with salt and water (Hollander et al., 1968), or by later medial hypertrophy or arteriosclerosis or both. This would splint the baroreceptor endings and reduce their sensitivity to a change in arterial pressure. Mitchell and Schwartz (1965) in a post mortem series found plaque formation in every carotid sinus examined when the subject was over the age of 35 years. The carotid sinus region appears especially prone to arterial degeneration, being second only to the iliac arteries in the frequency with which it was affected. Such a splinting mechanism would explain why Pickering et al. (1936) could not find any evidence of reduced baroreflex sensitivity in hypertension. Digital compression of a stiff sinus might still stimulate receptors. Indeed, the effect of digital compression of what was a previously 'silent' sinus might be expected to have a greater effect than normal. This could certainly be an explanation for the so-called carotid sinus syncope syndrome. We are currently correlating vessel wall distensibility with the reflex changes we observe.

Evidence that the baroreflex sensitivity may have little to do with long-term regulation of arterial pressure falls under two main heads:

(I) In a group of patients subjected to renal dialysis or nephrectomy, baroreflex sensitivity, measured before and after, does not change sig- nificantly, although the arterial pressure has been lowered to normal from previously high levels (B. Gribbin, D. O. Oliver, T. G. Pickering, and P. Sleight, 1970, unpublished). This is not conclusive evidence, since fixed changes in the arteries may have already occurred and the lowered arterial pressure may be due to changes in blood volume.

(2) In a group of patients with aortic incompetence we found extremely low baroreflex sensitivity, but there was no relation between this and the arterial pressure (T. G. Pickering and P. Sleight, 1970, unpublished). Again this is inconclusive; we do not know whether the change in reflex sensitivity is due to damage to the receptors or to 'saturation' of the receptors by the great increase in pulse pressure.

The mechanisms of blood pressure control are extremely complex. They have been likened to a 'mosaic' (Page, 1968) and the 'layers of an onion' (Dickinson, 1965); if one takes away one mechanism, another is there to take over. Whatever the factors responsible for the variability in arterial pressure from one individual or race to another, it is difficult to ignore entirely the influence of the autonomic nervous system. Whatever the type of hypertension, renal or 'essential', it is possible in the majority of cases to lower pressure with drugs which affect the autonomic nervous system. It is also possible to achieve longterm control by carotid sinus nerve stimulation (Schwartz and Griffith, 1967). Nestel (1969) has recently reported increased urinary excretion of catecholamines in subjects with borderline hypertension compared with normals during mental arithmetic.

Perhaps the genetic factors so important in hypertension express themselves through an increased activity of the sympathetic discharge to the heart and blood vessels or an increased vascular reactivity (Doyle and Fraser, 196I) leading to the high cardiac output or peripheral resistance we have already discussed. This high cardiac output type of hypertension found in young subjects does resemble the neurogenic hypertension seen in the experimental animal. It remains to be seen if these same subjects go on to develop essential hypertension as is suggested by epidemiological studies. An increased sympathetic discharge might be reflex in origin, might be determined by the action of angiotensin on the central nervous system (Scroop and Whelan, 1968), or might be a response to poorly understood environmental influences acting through the central nervous system (Folkow and Rubinstein, 1966).

The work reported here has been carried out with many colleagues: Dr. J. D. Bristow, Dr. B. Grib- 
bin, Dr. A. J. Honour, Dr. D. Oliver, Dr. H. Smyth, Prof. G. W. Pickering, Dr. T. G. Pickering, and Dr. C. Prys-Roberts. It has been supported by grants from the Medical Research Council, the British Heart Foundation, the Beit Memorial Trust, and the research funds of the United Oxford Hospitals.

\section{References}

Aars, H. (1968a). Aortic baroreceptor activity in normal and hypertensive rabbits. Acta Physiologica Scandinavica, 72, 298.

- (1968b). Static load-length characteristics of aortic strips from hypertensive rabbits. Acta Physiologica Scandinavica, 73, ror.

Ábrahám, A. (1969). Microscopic Innervation of the Heart and Blood Vessels in Vertebrates Including Man. Pergamon Press, Oxford.

Boyd, J. D., and McCullagh, G. P. (1938). Experimental hypertension following carotico-aortic denervation in the rabbit. Quarterly fournal of Experimental Physiology, 27, 293.

Bristow, J. D., Honour, A. J., Pickering, G. W., Sleight, P., and Smyth, H. S. (1969a). Diminished baroreflex sensitivity in high blood pressure. Circulation, 39, 48.

—, Prys-Roberts, C., Fisher, A., Pickering, T. G., and Sleight, P. (1969b). Effects of anesthesia on baroreflex control of heart rate in man. Anesthesiology, 31, 422.

Christensen, B. N., Warner, H. R., and Pryor, T. A. (1967). A technique for the quantitative study of carotid sinus behaviour. In Baroreceptors and Hypertension: Proceedings of an International Symposium, 1965, p. 4I. Ed. by P. Kezdi. Pergamon Press, Oxford.

Conway, J. W. (1969). Clinical significance of labile hypertension. In Hypertensive Cardiovascular Disease, p. 36. Ed. by A. N. Brest. Davis, Philadelphia.

Dickinson, C. J. (1965). Neurogenic Hypertension. Blackwell, Oxford.

Doyle, A. E., and Fraser, J. R. E. (1961). Essential hypertension and inheritance of vascular reactivity. Lancet, 2, 509 .

Folkow, B., and Rubinstein, E. H. (1966). Cardiovascular effects of acute and chronic stimulations of the hypothalmic defence area in the rat. Acta Physiologica Scandinavica, 68, 48.

Hollander, W., Kramsch, D. M., Farmelant, M., and Madoff, I. M. (1968). Arterial wall metabolism in experimental hypertension of coarctation of the aorta of short duration. Fournal of Clinical Investigation, 47, 1221 .
Julius, S., and Conway, J. 1968). Hemodynamic studies in patients with borderline blood pressure elevation. Circulation, 38, 282.

Khatri, I. M., and Freis, E. D. (1967). Hemodynamic changes during sleep. Fournal of Applied Physiology, 22, 867.

Koch, E., and Mies, H. (1929). Chronischer arterieller Hochdruck durch experimentelle Dauerausschaltung der Blutdruckzügler. Krankheitsforschung, 7, 241 .

Ledingham J. M. and Cohen, R. D. (1963). The role of the heart in the pathogenesis of renal hypertension. Lancet, 2, 979.

Lund-Johansen, P. (1967). Hemodynamics in early essential hypertension. Acta Medica Scandinavica, Suppl. 482.

McCubbin, J. W., Green, J. H., and Page, I. H. (1956). Baroceptor function in chronic renal hypertension. Circulation Research, 4, 205.

Mitchell, J. R. A., and Schwartz, C. J. (1965). Arterial Disease. Blackwell, Oxford.

Nestel, P. J. (1969). Blood-pressure and catecholamine excretion after mental stress in labile hypertension. Lancet, I, 692.

Page, I. M. (1968). A unifying view of renal hypertension. In Renal Hypertension, p. 391. Ed. by I. H. Page and J. W. McCubbin. Year Book Medical Publishers, Chicago.

Pickering, G. W. (1968). High Blood Pressure, 2nd ed. Churchill, London.

- Kissin, M., and Rothschild, P. (1936). The relationship of the carotid sinus mechanism to persistent high blood pressure in man. Clinical Science, 2, 193.

Richardson, D. W., Honour, A. J., Fenton, G. W., Stott, F. H., and Pickering, G. W. (1964). Variation in arterial pressure throughout the day and night. Clinical Science, 26, 445.

Schwartz, S. I., and Griffith, L. S. C. (1967). Reduction of hypertension by electrical stimulation of the carotid sinus nerve. In Baroreceptors in Hypertension: Proceedings of an International Symposium, 1965, p. 409. Ed. by P. Kezdi. Pergamon Press, Oxford.

Scroop, G. C., and Whelan, R. F. (1968). Vascular reactivity studies in hypertension. Australian fournal of Experimental Biology and Medical Science, 46, 555 .

Sivertsson, R. (1970). The hemodynamic importance of structural vascular changes in essential hypertension. Acta Physiologica Scandinavica, Suppl. 343.

Smyth, H. S., Sleight, P., and Pickering, G. W. (1969). Reflex regulation of arterial pressure during sleep in man; a quantitative method of assessing baroreflex sensitivity. Circulation Research, 24, 109. 